\title{
Meckel's Diverticulum: Should it be Excised Prophylactically in Service Personnel?
}

\author{
Maj (Retd) M J Farrar \\ FRCS(Ed), RAMC \\ Military Wing, Musgrave Park Hospital, BFPO 801
}

SUMMARY: In a four month period in 1992 at a small military wing of a civilian hospital three Meckel's Diverticulae were removed from patients suspected of having complications in their vermiform appendix. One of the diverticulae was inflamed and was the cause of the symptoms. The second was a symptomatic but it and the appendixes showed transmural granulomatous inflammation caused by infection with Yersinia pseudotuberculosis. The third $\vec{\circ}$ also asymptomatic was found to contain carcinoid tumour. On investigation with urinary estimations of $5 \mathrm{Hydroxy} \not \overrightarrow{.}$ Indole Acetic Acid there was no sign of residual carcinoid tumour in the patient. None of the patients has had com- $\omega$ plications from their surgery. Review of the literature shows that prophylactic excision of asymptomatic Meckel's Diverticulae to prevent possible complications is justified in persons under the age of 40 such as is the typical service population .

\section{Introduction}

Meckel's Diverticulum is the remnant of the fetal vitello intestinal duct. The incidence in the population is approximately $2 \%$ or one should be found in every 50 laparotomies if looked for. In most individuals who possess a Meckel's Diverticulum no symptoms are experienced in their lifetime. In a proportion however it can be symptomatic and of those a proportion can have fatal complications. An argument therefore exists as to whether incidentally discovered Meckel's Diverticulae should be prophylactically excised or left alone .

I report the interesting findings of three Meckel's Diverticulae discovered in patients who were operated on in the Military Wing, Musgrave Park Hospital during the Spring and Summer of 1992 suspected of having complications arising from their vermiform appendix.

\section{Case 1:}

A 30 year old man was investigated for recurrent abdominal pain with signs of subacute intestinal obstruction associated with a tender lower abdominal mass. In two previous admissions his pain had settled spontaneously with antibiotics and intravenous fluids.

Appendix Mass or Crohn's Disease were the main differential diagnoses and he was investigated with barium studies. These showed no large or small bowel abnormality but faeces in the lumen of the appendix.

He was admitted with a further, more severe episode of pain and a laparotomy was performed. An inflamed Meckel's Diverticulum was found within an inflammatory mass and there was evidence of intralumenal bleeding in the ileum. Histology confirmed an inflamed Meckel's Diverticulum with ectopic gastric mucosa.

\section{Case 2:}

An 18 year old girl was admitted with abdominal pain, acute appendicitis was diagnosed clinically and an inflamed appendix was removed. Inspection of the ileum revealed a wide mouthed Meckel's Diverticulum which was excised with a short section of ileum. A primary, anastomosis was performed.

Histology revealed transmural, granulomatous inflam-음 mation of both appendix and Meckel's Diverticuluma. $\rightarrow$ Serology confirmed recent infection with Yersir pseudotuberculosis which was supported by the patienge giving a recent history of camping out rough on the We hills in sheep fields.

\section{Case 3:}

An 18 year old man was admitted with abdominal parto acute appendicitis was diagnosed clinically and app dicectomy was performed.

The appendix was normal and a few enlarged mesen teric lymph nodes were found, one of which was removedo for histology. On inspection of the ileum, a Meckel's Diverticulum was found which was excised with a wedgeg of ileum.

Histology confirmed non-inflamed appendix and non specific reactive lymph node. The diverticulum howeve contained a small nest of carcinoid tumour.

The patient was subsequently investigated with three 24 hour urine collections for 5-Hydroxy Indole Acetic Acid Two of these were normal, the third was slightly raised in keeping with dietary intake.

Six months since the last of these cases no patient hasio been re-admitted with any complication.

\section{Discussion}

These three Meckel's Diverticulae represent the number which would be found in 150 appendix operations or that which would only be found in a period of severa? years in a small military hospital.

An argument exists whether incidentally found Meckel's Diverticulae, as in cases $2 \& 3$, should be proc phylactically excised or not when operating for abdominat pain. The main arguments for are that : 
1. Meckel's Diverticulum can be the site of ectopic gastric or pancreatic tissue, which can lead to the complications of peptic ulceration and inflammation respectively.

2. Mechanical complications such as band obstruction, perforation, intussusception and hernial entrapment can occur.

3. More rarely Meckel's Diverticulum can be the site of malignancy.

When operating on patients for clinically diagnosed acute appendicitis some practical guidelines have been suggested (1). Firstly if the clinical diagnosis is correct no further search in the abdomen should be undertaken and the operation terminated. Secondly if the appendix is normal there should be a search for further pathology and if any found, such as a Meckel's Diverticulum, then it should be removed.

Some say that a wide mouthed diverticulum can be safely left in such cases unless there is palpable abnormality of the mucosa. This particular argument is not supported by a Swedish study (2) which showed symptomatic Meckel's Diverticulae are longer and have wider mouths than asymptomatic ones. Diverticulae over $2 \mathrm{~cm}$ in length were seen to be more likely symptomatic in another study (4) . Palpation for ectopic mucosa in a Meckel's Diverticulum has been shown to be only approximately $50 \%$ accurate $(2,3)$ which lends more weight to the view that all Meckel's Diverticulae should be removed rather than left when operating for abdominal pain.

The question whether there is scientific evidence for prophylactic excision of Meckel's Diverticulum should be addressed. Meckel himself stated that $25 \%$ of his diverticulae were symptomatic. This view has been used by surgeons in the past as justification to remove all those found incidentally. In two large retrospective studies $(5,6)$ this has not been found. Lifetime risk of having complications from a Meckel's Diverticulum was calculated in both studies to be about $4 \%$ in patients up to 20 years of age, $2 \%$ up to 40 and approaching $0 \%$ in old age. The mortality from symptomatic Meckel's Diverticulae has been reported as high as $10 \%$ (4) with a generally accepted average of $6-7 \%$ in other studies $(4,5)$.

The complication rates from excision of asymptomatic diverticulae are reported ranging from $1.2 \%$ to $8 \%$ $(2,3,4,5,6,7)$. The most common complication is simple adhesive intestinal obstruction with few cases requiring further surgery. Bleeding from resection line, dehiscence and incisional hernia have also been reported. There was only one report of a single mortality directly attributable to prophylactic resection of a Meckel's Diverticulum (2). Like this report, most smaller series record no mortality and little morbidity.

The overall feeling in the quoted studies which report some 900 cases (and in many other smaller studies not quoted) is that prophylactic excision of asymptomatic Meckel's Diverticulae can only be justified to prevent complications in young patients. In those over $30-40$ years of age the risk from complications from the resec- tion outweighs the benefit. The conservative view not to resect and keep the individual under review has been put forward (2). This would be less likely to be acceptable in a young, frontline soldier whose continuing fitness to serve is paramount.

In this series there is no doubt that the patient in Case 1 required excision. In Case 2 there was no direct benefit from excision except to support diagnosis of a benign condition.

Case 3 however exhibited a rare but potentially fatal complication, a carcinoid tumour.

The most recent authoritative article on carcinoid of the Meckel's Diverticulum (8) shows that since the first report in 1907 there have only been 109 other such carcinoids reported. This still makes it the most common malignant tumour of the Meckel's Diverticulum, the second being leiomyosarcoma .

The metastatic potential of these particular carcinoids is much greater than those of the appendix (9). Had this patient's diverticulum not been resected the tumour would probably have grown and he might have gone on to develop carcinoid syndrome.

\section{Conclusion}

Johann Frederick Meckel described his diverticulum in 1809. In 1953 Thorek gave us the mnemonic "disease of twos":

2 percent of the population 2 times more common in males

2 feet from the ileocaecal valve 2 inches long

2 types of ectopic tissue (pancreatic and gastric)

2 complications (haemorrhage and inflammation)

Others say it is too important to forget. The experience of this small series is that in young Service personnel removing incidentally found Meckel's Diverticulae is justified and is associated with minimal risk of complications.

\section{REFERENCES:}

1. Editorial Meckel's Diverticulum. Surgical guidelines at last? Lancet 1983; 2: 438-439.

2. Lejonmarck C -E et al. Meckel's Diverticulum in the adult. BrJ Surg 1986; 73: 146-149.

3. LANG-STEvenson A. Meckel's Diverticulum: to look or not to look: to resect or not to resect. Ann R Coll Surg Engl 1983; 65: 218-220

4. MaCKey W DineEN P. A fifty year experience with Meckel's Diverticulum. Surg Gynecol Obstet 1983; 156: 56-64.

5. SOltero M, Bill A. The natural history of Meckel's Diverticulum and its relation to incidental removal. Am J Surg 1976; 132: 168-173.

6. LUDTKE F, et al. Complications and management of Meckel's Diverticulum. Surg Gynecol Obstet 1989; 169: 537-542, 
7. Michas C, Cohen S. Wolfman E. Meckel's Diverticulum. Should it be excised incidentally at operation? Am J Surg 1975; 129: 682-685

8. Weber J, MCFadden D. Carcinoid tumours in Meckel's Diverticula. J Clin Gastroenterol 1989; 11: 682-686.
9. MoYana T. Carcinoid tumours arising from Meckel's Diverticulum, A clinical, morphologic and immuno histochemical study. Am J Clin Pathol 1989; 91: 52@ 56. 